\title{
Study on the interface characteristics of the weak base ASP flooding produced liquid
}

\author{
Fengyun $\mathrm{HE}^{1,}$, , Xiao $\mathrm{LIANG}^{1, \mathrm{~b}}$, Yanan $\mathrm{LV}^{1, \mathrm{c}}$, Yilan $\mathrm{LI}^{1, \mathrm{~d}}$, Jing DONG ${ }^{1, \mathrm{e}}$ \\ ${ }^{1}$ School of Petroleum Engineering, Northeast Petroleum University, Daqing, China, 163318 \\ a1461322868@qq.com, b2439624184@qq.com, ${ }^{c} 1229576721 @ q q . c o m,{ }^{d} 339091569 @ q q . c o m$ \\ edongjingnepu@163.com
}

Keywords: ASP flooding; Produced liquid; Weak base; Interface characteristics

Abstract. ASP flooding has been proved to be an effective method to enhance oil recovery. But residual alkaline in produced liquid have resulted in stable crude oil emulsion, the difficulty of separating oil and water is obviously increased. Based on interface tension experiment, emulsification experiment and potential experiment, this paper studied the weak base ASP flooding. Experimental results show that: the stronger the alkalinity, the greater the degree of emulsification, the more stable the emulsion, the more difficult to separate water and oil. The emulsifying capacity of weak base ASP flooding is less than strong base ASP flooding.

\section{Introduction}

For ASP Flooding, strong base has synergistic effect which using $\mathrm{NaOH}$ as alkali agent, but also brought many negative effects. For example, the viscosity of the system decreased, and scaling in the oil well and oil reservoir was restricted to the promotion and application of the compound flooding ${ }^{[1,}$ ${ }^{2]}$.So it is necessary to replaced by weak base which using $\mathrm{Na}_{2} \mathrm{CO}_{3}$ as alkali agent. Weak base ASP flooding has been applied in the field text of Daqing Oilfield, this technology has obtained certain result. However, the residual alkali in the produced liquid had a certain influence on the degree of emulsification, the degree of oil-water separation and the interfacial properties of oil and water. So we need to make a study on interface characteristics of weak base ASP flooding produced liquid. It aims to lay the theoretical foundation for produced liquid oil-water separation process and promote the application of weak base ASP flooding in oil field.

\section{Contrasting the Zeta potential}

Potential of oil-water interface was descended, for surfactant created in the system of alkali, colloid and asphaltene. The compression effect of alkali on the interfacial diffusion of electric double layer makes the potential rise.

Oil-water interface of ASP flooding produced liquid carry excess negative charge, Zeta potential of diffused double layer is the negative figures.

Table 1 the absolute value of Zeta potential of the ASP flooding produced liquid with different alkalis

\begin{tabular}{|c|c|c|c|c|}
\hline Concentration & $\begin{array}{c}\text { Concentration of } \\
\mathrm{Na}_{2} \mathrm{CO}_{3} \\
{[\mathrm{ppm}]}\end{array}$ & $\begin{array}{c}\text { Concentration of } \\
\text { active agent } \\
{[\mathrm{ppm}]}\end{array}$ & $\begin{array}{c}\text { Polymer } \\
\text { concentration } \\
{[\mathrm{ppm}]}\end{array}$ & $\begin{array}{c}\text { Zeta potential } \\
{[\mathrm{mV}]}\end{array}$ \\
\hline Strong base & 1000 & 130 & 1300 & 69.26 \\
\hline Weak base & 1000 & 130 & 1300 & 55.53 \\
\hline Water flooding & 0 & 0 & 0 & 14.78 \\
\hline
\end{tabular}

According to the table 1, it can be seen that the Zeta potential value of weak base ASP flooding is less than strong base ASP flooding; the Zeta potential value of water drive produced liquid is the lowest. The smaller the absolute value of Zeta potential, the smaller the repulsion force between the droplets, the weaker the ability of the polymer, the lower the emulsion stability. 


\section{Contrasting the interfacial tension}

Low interfacial tension is the contribution of active substances adsorbing to the oil-water interface, it is caused by the active matter generating in the reaction between alkali in water phase and organic acid in crude oil, after alkali had a good contact with crude oil. Because of the decrease of IFT of oil and water, the electronegativity will be enhanced, the diameter of oil will be decreased, the extent of emulsification will be increased and the coalescence of oil pearl and water drop will be difficult ${ }^{[3]}$.

Table 2 the measured value of oil-water interfacial tension in different chemical agents

\begin{tabular}{|c|c|c|c|c|c|c|}
\hline \multirow[b]{2}{*}{ Number } & \multirow{2}{*}{$\begin{array}{c}\text { Temperature } \\
{\left[{ }^{\circ} \mathrm{C}\right]}\end{array}$} & \multirow{2}{*}{$\begin{array}{c}\text { Revolving } \\
\text { speed } \\
{[\mathrm{r} / \mathrm{min}]}\end{array}$} & \multicolumn{3}{|c|}{ Chemical agent } & \multirow{2}{*}{$\begin{array}{c}\text { Interfacial } \\
\text { tension } \\
{[\mathrm{mN} / \mathrm{m}]}\end{array}$} \\
\hline & & & $\begin{array}{l}\text { Alkali } \\
{[\mathrm{ppm}]}\end{array}$ & $\begin{array}{l}\text { Active agent } \\
\text { [ppm] }\end{array}$ & $\begin{array}{c}\text { Polymer } \\
\text { [ppm] }\end{array}$ & \\
\hline 1 & 50 & 5000 & \multicolumn{3}{|c|}{ Simulation of water } & 23 \\
\hline 2 & 50 & 5000 & $1000\left(\mathrm{Na}_{2} \mathrm{CO}_{3}\right)$ & 130 & 1300 & 1.656 \\
\hline 3 & 50 & 5000 & $1000(\mathrm{NaOH})$ & 130 & 1300 & 0.173 \\
\hline
\end{tabular}

According to table 2, we can see that the same concentration of strong base and the weak base mixed with oil, interfacial tension of the two-phase is different. Interfacial tension of weak base ASP flooding produced liquid is larger than the strong base, processing difficulty is small, emulsion stability is decreased, oil-water separation difficulty is decreased. It is favorable to crude dehydration.

\section{Contrasting the interface strength}

Under the effect of shear stress, and in the proportional limit range of the elastic deformation, the ratio of shear stress and shear strain is the shear elastic modulus. It is the ability of a material to resist shear strain. The larger shear elastic modulus are, the more difficult to break the interfacial film, the more stable the emulsion is.

The concentration of alkali, surfactant and polymer are $1000 \mathrm{mg} / \mathrm{L}, 130 \mathrm{mg} / \mathrm{L}$ and $1300 \mathrm{mg} / \mathrm{L}$. The measured shear elastic modulus, viscous modulus and composite modulus compared with the same concentration of weak base. The comparison results are shown in Fig. 1.

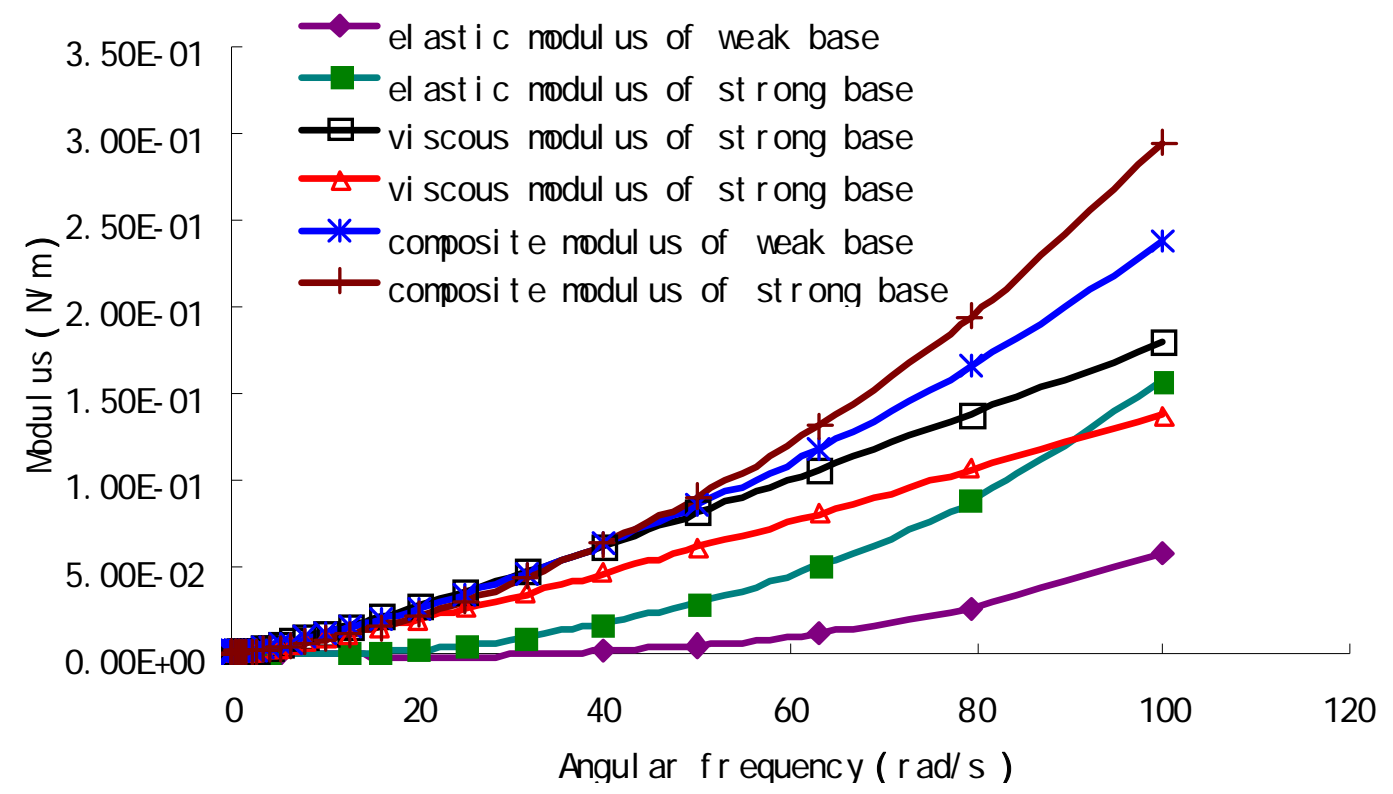

Fig. 1 the contrast of interface elastic modulus, viscous modulus and composite modulus between weak base and strong base

When the angular frequency is $100 \mathrm{rad} / \mathrm{s}$, interface elastic modulus, viscous modulus and composite modulus of water flooding produced liquid are $0.05283 \mathrm{~N} / \mathrm{m}, 0.04831 \mathrm{~N} / \mathrm{m}, 0.10114 \mathrm{~N} / \mathrm{m}$. All values are below the value of weak base asp flooding. The value of elastic modulus and composite modulus of 
strong base ASP flooding processes is greater then weak base ASP flooding processes. The value of viscous modulus of strong base ASP flooding processes is less then weak base ASP flooding processes. Weak base ASP flooding is favorable to crude dehydration.

The interfacial shear viscosity is an important property of interface molecular film ${ }^{[4]}$. It can reflect the interfacial film strength.

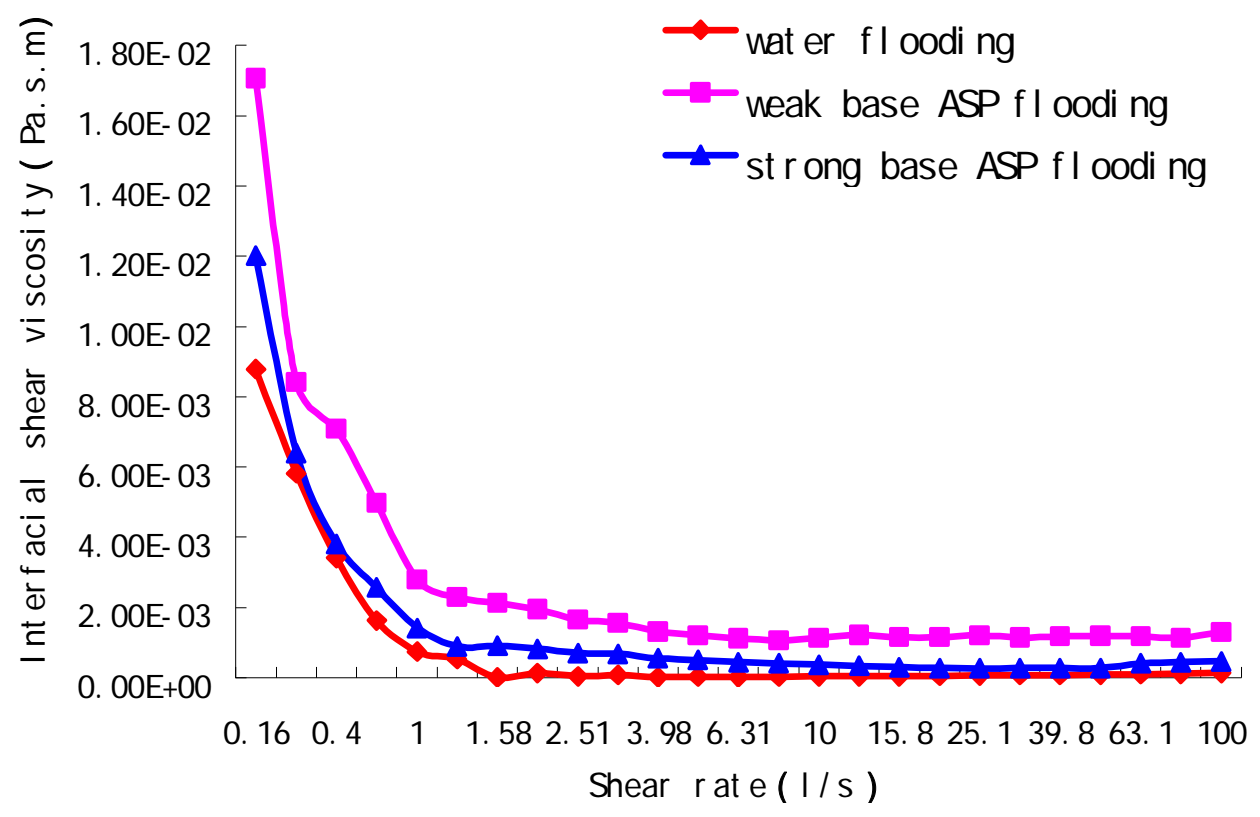

Fig. 2 the contrast of interfacial viscosity between weak base and strong base

Interfacial viscosity is bigger, the more stable the emulsion. We can see from Fig. 2, the value of interfacial viscosity of strong base ASP flooding processes is less then the value of weak base ASP flooding processes.

The value of interface elastic modulus, viscous modulus, composite modulus and interfacial viscosity of weak base is greater than the value of ordinary water flooding produced liquid.

\section{Conclusions}

1. Zeta potential value of weak base ASP flooding is less than strong base ASP flooding. The smaller the absolute value of Zeta potential, the smaller the repulsion force between the droplets, the weaker the ability of the polymer. It is conducive to the separation of oil and water

2. Interfacial tension of weak base ASP flooding produced liquid is larger than the strong base, the emulsion stability is poor, the difficulty of oil water separation is small, which is favorable for the dehydration of crude oil.

3. Interface strength of weak base ASP flooding produced liquid is less than the strong base. The stability of emulsion is low, which is beneficial to the separation of oil and water.

\section{References}

[1] Jia Q, Zhou B, Zhang R L, et al. Development and application of a silicate scale inhibito for ASP flooding production scale[R]. SPE74675, 2002:1-4.

[2] Wang Y P, Liu J D, Liu B, et al. Why does scale form in ASP flood ? How to prevent from it-A case study of the technology and application of scaling mechanism and inhibition in ASP flood pilot area of N-1DX block in Daqing[R]. SPE87469, 2004:1-6.

[3] Nedjhioui M, Moulai M N, Morsli A, et al. Combined effects of polymer/surfactant/oil/alkali on physical chemical properties[J]. Desalination, 2005, 185(1/2/3): 543-550.

[4] LiMingyuan, XuMingjin, MaYu, etal. Interfacialfilm properties of asphaltenes and resins[ J] .Fuel, 2002, 81:1847-1853. 